\title{
Outdated contract for rural doctors is affecting patient care
}

\author{
— Cite as: CMAJ 2018 May 14;190:E605-6. doi: 10.1503/cmaj.109-5599
}

Posted on cmajnews.com on Apr. 26, 2018.

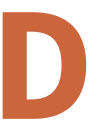
octors in rural and northern Ontario say their outdated contract is making it difficult to recruit physicians and find locum doctors, and it's affecting access to care. The Rural and Northern Physician Group Agreement (RNPGA) was conceived in 1996 to attract doctors to remote communities. There are 37 rural and northern communities funded under the agreement, which applies to areas with seven or fewer physicians.

"There was a huge issue in the mid ' 90 s with a number of emergency departments in danger of closing because of a lack of physicians," said Dr. Stephen Cooper, who works under the RNPGA in Little Current, Ontario. The agreement was introduced to bring more income stability to rural practices, where "the volumes tend to be lower but the complexity higher." In the first decade, the agreement "made a huge difference in recruiting both locums and permanent physicians," said Cooper, but it no longer appears to be effective. "It's starting to feel like it did in the early 1990s."

Cooper thinks the RNPGA needs to be updated to reflect changes in medical practice over the past two decades. In addition, more medical trainees are moving to rural centres for training, which is positive but it takes physicians' time away from patient care. "It's not about higher salaries," he said. "We need funding for more providers."

There have been minor tweaks to the RNPGA over the years, but "it hasn't kept up in parallel with all the other changes that happened across the province," said Dr. Lisa Habermehl, a family physician and chair of the Ontario Medical Associa-
Hutten-Czapski, who practises in Temiskaming Shores. Payment for locum coverage is actually more generous under the RNPGA than other team-based models. But at $\$ 775$ for the base daily stipend, it's still below market rate. That amount doesn't adequately reimburse doctors for travel time, according to physicians interviewed.

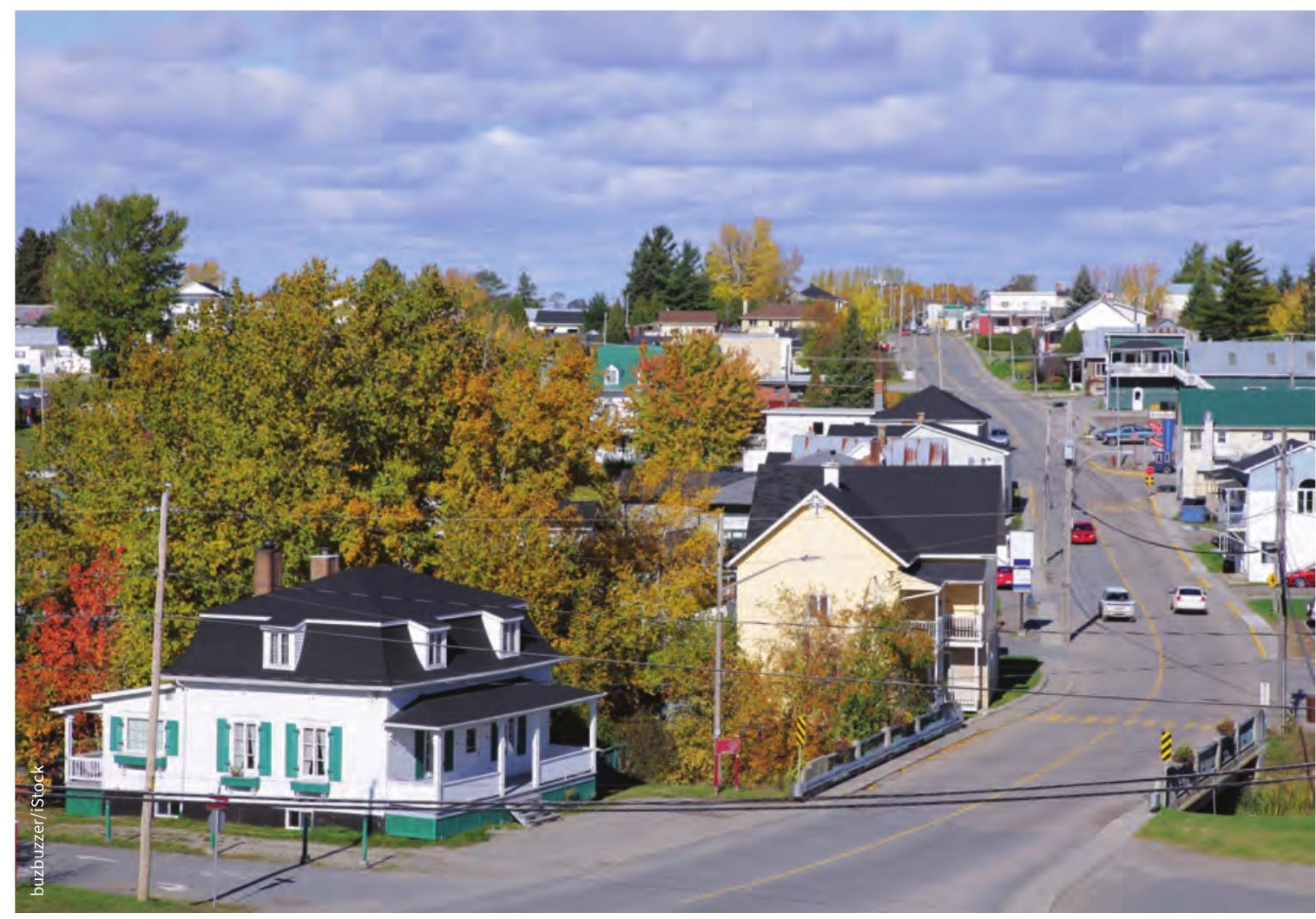

Recruiting physicians to rural communities is an ongoing struggle in Canada. tion Rural Forum, pointing to the introduction of models such as Family Health Networks and Family Health Organizations in the mid-2000s.

Emergency and inpatient care are not as adequately remunerated as under more recent team models, said Dr. Peter
Hutten-Czapski said his community has been trying to fill a position for more than six years. His group just lost another doctor, so they are two short of the sixmember team they're supposed to have. "We are getting a little stressed in terms of the number of patients," he said. "It 
means that people are waiting longer. It's affecting access to care."

Dr. Sarah Newbery, a family physician in Marathon, said the urban team models have "levelled the playing field in a way that has disadvantaged rural communities," adding that an uneven playing field is necessary to recruit doctors to demanding practices in geographically isolated areas.

The once-effective RNPGA is in need of an overhaul, said Newbery. "I'm hearing [reluctance] from new grads. Why would they come to Marathon, when they can make just as much and actually have an easier practice lifestyle in an urban setting?"
The majority of the time, rural doctors can't find a locum to cover for them, said Dr. Andrew Gloster, lead physician at the Red Lake Family Health Team. That means fewer primary care appointments for patients in RNPGA communities. Another problem relates to role splitting. Often, two or three physicians split the role of a single doctor, because their spouses work and live outside the community. But the bonus provided to one full-time doctor can't be split among more than one doctor, said Gloster.

David Jensen, spokesperson for the Ontario Ministry of Health and Long-Term Care, pointed out several advantages the RNPGA has over other group contracts, including the more generous locum support and flexibility for physicians to split a full-time position. Jensen, who provided comment by email, could not say whether the government is open to changing the agreement, given that contract negotiations with the province's doctors are ongoing.

According to Dr. Shawn Whatley, president of the Ontario Medical Association, the contract hasn't come up in negotiations, but all primary care models, including the RNPGA, are scheduled to be discussed during the arbitration process with the Ontario government.

Wendy Glauser, Toronto, Ont. 